\title{
A SUSTENTABILIDADE E SUAS DIMENSÕES
}

\section{SUSTAINABILITY AND ITS DIMENSIONS}

\section{Beatriz Oliveira Iaquinto ${ }^{1}$}

Resumo: A sustentabilidade está cada vez mais presente na vida de todos os indivíduos, ainda que esses não percebam, em razão da sua grande abordagem no mundo todo como uma forma de amenizar os problemas ambientais que o próprio ser humano causa ao planeta Terra. Assim, surgem as "dimensões da sustentabilidade", as quais tratam justamente da forma como a sustentabilidade aparece nas mais diversas relações humanas. Logo, o objeto do presente artigo é analisar a sustentabilidade e a importância que ela exerceem diversas áreas da sociedade. O objetivo geral é explicar e definir a sustentabilidade e suas dez dimensões, quais sejam: dimensão ecológica ou ambiental, dimensão econômica, dimensão social, dimensão espacial ou territorial, dimensão cultural, dimensão política (nacional e internacional), dimensão jurídico-política, dimensão ética, dimensão psicológica e dimensão tecnológica. $\mathrm{O}$ método a ser utilizado é o indutivo, com base em pesquisa bibliográfica, bem como em obras dos principais doutrinadores ambientalistas. Em linhas gerais, é nesse universo que será desenvolvida a pesquisa, restando, assim, caracterizada a sua relevância social e contribuição à ciência jurídica.

Palavras-chave: Sustentabilidade. Desenvolvimento Sustentável. Dimensões da Sustentabilidade.

Abstract: Sustainability is increasingly present in the lives of all individuals, even if they do not perceive it, because of its great approach in the whole world as a way to soften the environmental problems that the human being itself causes to the planet Earth. Thus, the "dimensions of sustainability" arise, which deal precisely with the way in which sustainability appears in the most diverse human relations. Therefore, the purpose of this article is to analyze the sustainability and the importance it exerts in several areas of society. The general objective is to explain and define sustainability and its ten dimensions: ecological or

1 Bacharela em Direito pela Universidade do Vale do Itajaí - UNIVALI, pós-graduanda em Direito Público pela Escola Superior da Magistratura do Estado de Santa Catarina - ESMESC. Residente Judicial no Tribunal de Justiça do Estado de Santa Catarina. Email: iaquintobeatriz@gmail.com. 
environmental dimension, economic dimension, social dimension, spatial or territorial dimension, cultural dimension, political dimension (national and international), legal-political dimension, ethical dimension, psychological dimension and technological dimension. The method to be used is the inductive one, based on bibliographical research, as well as in the works of the main environmentalist indoctrinators. In general, it is in this universe that the research will be developed, thus remaining characterized its social relevance and contribution to legal science.

Keywords: Sustainability. Sustainable Development. Dimensions of Sustainability.

\section{INTRODUÇÃ̃O}

O presente artigo tem como objeto a análise da sustentabilidade e a verificação da sua importância em diversas áreas da sociedade, tendo em vista que a sustentabilidade se mostra como uma alternativa para a amenização da destruição ambiental e recuperação do meio ambiente, bem como uma nova forma de conscientização das pessoas com relação ao modo que devem agir em busca de um bem maior, qual seja, a preservação da mãe Terra e, consequentemente, a garantia de condições de existência para todos os seres vivos.

Dessa forma, o grande objetivo do trabalho em apreço é o de conceituar o termo sustentabilidade e, principalmente, analisar as suas dimensões, ou seja, as diversas áreas em que a sustentabilidade exerce influência.

Para tanto, serão abordadas dez dimensões da sustentabilidade, quais sejam: dimensão ecológica ou ambiental, dimensão econômica, dimensão social, dimensão espacial ou territorial, dimensão cultural, dimensão política (nacional e internacional), dimensão jurídico-política, dimensão ética, dimensão psicológica e dimensão tecnológica.

Assim, a partir do estudo de cada uma das dimensões da sustentabilidade será possível verificar e compreender como a sustentabilidade está em praticamente todas as relações humanas 
e o quanto a sua presença é de suma importância para que seja possível atingir um meio ambiente ecologicamente equilibrado.

\section{CONCEITO DE SUSTENTABILIDADE}

A palavra sustentabilidade tem ao longo dos anos ganhado um grande destaque no cenário nacional e internacional, devido à eclosão de grandes problemas ambientais no planeta Terra.

Tais problemas nada mais são do que consequências das atitudes agressivas do ser humano para com a natureza, que busca cada vez mais retirar recursos do meio ambiente para satisfazer suas necessidades, sem possuir a consciência de que os referidos recursos são finitos e necessários para a sobrevivência humana, o que acaba por criar uma verdadeira crise ambiental.

Todo esse caos ambiental pode ser descrito da seguinte forma:

A situação atual se encontra, social e ecologicamente, tão degradada que a continuidade da forma de habitar a Terra, de produzir, de distribuir e de consumir, desenvolvida nos últimos séculos, não nos oferece condições de salvar a nossa civilização e, talvez até, a própria espécie humana; daí que imperiosamente se impõe um novo comę̧o, com novos conceitos, novas visões e novos sonhos, não excluídos os instrumentos científicos e técnicos indispensáveis; trata-se sem mais nem menos, de refundar o pacto social entre os humanos e o pacto natural com a natureza e a Mãe Terra. (BOFF, 2012, p. 15).

Assim, a sustentabilidade se mostra a solução para que uma nova consciência seja criada em cada indivíduo e para que haja uma melhora gradativa no meio ambiente.

Para entender melhor a sustentabilidade, pode-se dizer que tal termo significa:

[...] o conjunto dos processos e ações que se destinam a manter a vitalidade e a integridade da Mãe Terra, a preser- 
vação dos seus ecossistemas com todos os elementos físicos, químicos e ecológicos que possibilitam a existência e a reprodução da vida, o atendimento das necessidades da presente e das futuras gerações, e a continuidade, a expansão e a realização das potencialidades da civilização humana em suas várias expressões. (BOFF, 2012, p. 14).

E ainda:

[...] princípio constitucional que determina, com eficácia direta e imediata, a responsabilidade do Estado e da sociedade pela concretização solidária do desenvolvimento material e imaterial, socialmente inclusivo, durável e equânime, ambientalmente limpo, inovador, ético e eficiente, no intuito de assegurar, preferencialmente de modo preventivo e precavido, no presente e no futuro, o direito ao bem-estar. (FREITAS, 2012, p. 41).

Neste contexto, cabe realizar algumas ressalvas acerca da diferença existente entre os termos sustentabilidade e desenvolvimento sustentável, bem como sobre a evolução dos conceitos dessas expressões ao longo do tempo.

Em primeiro lugar, no que tange ao desenvolvimento sustentável, tem-se que tal terminologia surgiu na Conferência Mundial de Meio Ambiente, que ocorreu no ano de 1972, em Estocolmo, e após este evento, passou a ser utilizada nas demais conferências relativas ao meio ambiente. (FIORILLO, 2013, p. 56).

O conceito de desenvolvimento sustentável foi apresentado pela Comissão Mundial sobre Meio Ambiente e Desenvolvimento, em 1987, na Noruega, oportunidade em que foi formulado o Relatório de Brundtland, também chamado de "Nosso Futuro Comum”. (SCHRAMM; CORBETTA, 2015, p. 34-35).

Como conceito então para desenvolvimento sustentável, adotou-se o seguinte:

O desenvolvimento que procura satisfazer as necessidades 
da geração atual, sem comprometer a capacidade das gerações futuras de satisfazerem as suas próprias necessidades, significa possibilitar que as pessoas, agora e no futuro, atinjam um nível satisfatório de desenvolvimento social e econômico e de realização humana e cultural, fazendo, ao mesmo tempo, um uso razoável dos recursos da terra e preservando as espécies e os habitats naturais. (SCHRAMM; CORBETTA, 2015, p. 35).

Atualmente, é possível encontrar a consagração dessa expressão como princípio na Constituição da República Federativa do Brasil de 1988, em seu artigo 225, caput: "Todos têm direito ao meio ambiente ecologicamente equilibrado, bem de uso comum do povo e essencial à sadia qualidade de vida, impondo-se ao Poder Público e à coletividade o dever de defendê-lo e preservá-lo para as presentes e futuras gerações". (BRASIL, 1988).

Entretanto, deve-se ter em mente que desenvolvimento sustentável e sustentabilidade não são sinônimos.

Pode-se dizer que o "[...] desenvolvimento sustentável é uma locução verbal em que se ligam dois conceitos. O conceito de sustentabilidade passa a qualificar ou caracterizar o desenvolvimento". (MACHADO, 2015, p. 61). Ou seja, é possível afirmar que sustentabilidade é o processo que tem por finalidade atingir o desenvolvimento sustentável e, por sua vez, o desenvolvimento sustentável é o objetivo a ser alcançado. (SARTORI; LATRÔNICO; CAMPOS, 2012).

Neste cenário, surgiu o Triple Botton Line (a linha das três pilastras) criada por John Elkington (ELKINGTON, 2012, p. 107), que ensina que para que haja o desenvolvimento sustentável, esse deve ser economicamente viável, por exemplo, quando ocorrem as criações de empreendimentos, ambientalmente correto na interação de processos com o meio ambiente, a fim de não causar danos irreversíveis, e socialmente justo para a sociedade em geral para, por conseguinte, ocorrer a garantia e o 
alcance da sustentabilidade. (OLIVEIRA, 2012, p. 70-82).

Contudo, é imprescindível também anotar que muitos autores consideram que as palavras "desenvolvimento" e "sustentabilidade" são antagônicas e, por isso, impossíveis de caminharem juntas, rumo a um "desenvolvimento sustentável", senão vejamos:

[...] desenvolvimento e sustentabilidade obedecem a lógicas diferentes e que se contrapõem. O desenvolvimento, como vimos, é linear, deve ser crescente, supondo a exploração da natureza, gerando profundas desigualdades - riquezas de um lado e pobreza do outro - e privilegia a acumulação individual. Portanto, é um termo que vem do campo da economia política industrialista/capitalista. A categoria sustentabilidade, ao contrário, provém do âmbito da biologia e da ecologia, cuja lógica é circular e includente. Representa a tendência dos ecossistemas ao equilíbrio dinâmico, à cooperação e à coevolução, e responde pelas interdependências de todos com todos, garantindo a inclusão de cada um, até dos mais fracos. Se esta compreensão for correta, então fica claro que sustentabilidade e desenvolvimento configuram uma contradição nos próprios termos. Eles têm lógicas que se autonegam: uma privilegia o indivíduo, a outra o coletivo; uma enfatiza a competição, a outra a cooperação; uma a evolução do mais apto, a outra a coevolução de todos juntos e inter-relacionados. (BOFF, 2012, p. 45).

Por fim, analisando o que foi exposto acerca do conceito e aplicação da sustentabilidade nos dias atuais, conclui-se que esta é indiscutivelmente essencial em todas as áreas da sociedade e em todas as atividades humanas, porquanto, significa uma verdadeira interação entre o ser humano e o meio ambiente, de forma a se alcançar um equilíbrio ambiental e um verdadeiro amor àquilo que mantém o homem vivo.

\section{DIMENSÕES DA SUSTENTABILIDADE}

Como visto no tópico anterior, diante dos problemas eco- 
lógicos que o planeta Terra tem enfrentado, é imperioso que a sustentabilidade seja enquadrada no modo de vida de todos os indivíduos para, assim, tentar-se reverter os danos até então causados à mãe natureza e também impedir que ela seja ainda mais agredida pelas devastadoras ações humanas.

Diante desse quadro, foram criadas várias "dimensões" da sustentabilidade, que têm por objetivo realizar o estudo e compreensão da sustentabilidade em diversas áreas existentes nas relações humanas, como, por exemplo, econômica e social, para fomentar a sua prática e a incorporar de forma definitiva e, principalmente, efetiva na sociedade. (BRAUN; ROBL, 2015, p. 77).

Na pesquisa em apreço, serão retratadas dez dimensões da sustentabilidade, quais sejam, ecológica, econômica, social, cultural, espacial, política (nacional e internacional), jurídico-política, ética, psicológica e tecnológica, que serão conceituadas e analisadas a seguir.

\section{a) Dimensão ecológica ou ambiental}

Inicialmente, analisar-se-á a dimensão ecológica, também chamada de dimensão ambiental, da sustentabilidade, a qual:

[...] configura-se crescentemente como uma questão que envolve um conjunto de atores do universo educativo, potencializando o engajamento dos diversos sistemas de conhecimento, a capacitação de profissionais e a comunidade universitária numa perspectiva interdisciplinar. Nesse sentido, a produção de conhecimento deve necessariamente contemplar as inter-relações do meio natural com o social, incluindo a análise dos determinantes do processo, o papel dos diversos atores envolvidos e as formas de organização social que aumentam o poder das ações alternativas de um novo desenvolvimento, numa perspectiva que priorize novo perfil de desenvolvimento, com ênfase na sustentabilidade socioambiental. (JACOBI, 2003, p. 190). 
A partir desse primeiro entendimento, é possível verificar que a dimensão ambiental da sustentabilidade busca a preservação do meio ambiente, não sob uma concepção individualista, mas de forma transindividual. (ANJOS; UBALDO, 2015, p. 287).

Nesta dimensão, deve-se compreender que a grande questão é assegurar a criação de condições que tornem viável a vida no planeta Terra. (PÓVOAS, 2015, p. 49).

\section{Destarte:}

Considera-se, portanto, em dimensão ambiental, as inúmeras intervenções da sociedade na construção do espaço em que a prudência na utilização dos recursos naturais, tais como o solo, a água, dentre outros, sinaliza a importância de precaver as formas de ocupação em determinadas áreas suscetíveis a modificações provocando riscos diversos ao ambiente e à vida em um sentido amplo. (SILVA; SOUZA; LEAL, 2012, p. 31).

Sachs (1993, p. 26), por sua vez, enfatiza que para que a dimensão ora estudada seja posta em prática concretamente é necessário o uso de algumas alavancas, como a redução da quantidade de resíduos e de poluição, por meio da conservação e reciclagem de energia e recurso; o estabelecimento de regras para uma adequada proteção ambiental, assim como uma adequada escolha do conjunto de instrumentos econômicos, legais e administrativos necessários para assegurar o cumprimento das regras.

Sem demora, para que a dimensão ambiental faça parte da realidade de toda a população, é necessária:

[...] a preservação dos recursos naturais na produção de recursos renováveis e na limitação de uso dos recursos nãorenováveis; limitação do consumo de combustíveis fósseis e de outros recursos esgotáveis ou ambientalmente prejudiciais, substituindo-os por recursos renováveis e inofensivos; redução do volume de resíduos e de poluição, por meio de 
conservação e reciclagem; autolimitação do consumo material; utilização de tecnologias limpas; definição de regras para proteção ambiental. (MENDES, 2017, p. 51).

Finalmente, para Freitas (2012, p. 64-65), a dimensão ecológica pode ser resumida da seguinte forma:

Quer-se aludir, com a dimensão propriamente ambiental da sustentabilidade, ao direito das gerações atuais, sem prejuízo das futuras, ao ambiente limpo, em todos os aspectos (meio ecologicamente equilibrado, como diz o art. 225 da CF).[...] Em suma, (a) não pode haver qualidade de vida e longevidade digna em ambiente degradado e, que é mais importante, no limite, (b) não pode sequer haver vida humana sem o zeloso resguardo da sustentabilidade ambiental, em tempo útil, donde segue que (c) ou se protege a qualidade ambiental ou, simplesmente, não haverá futuro para a nossa espécie.

Portanto, por meio da dimensão ecológica ou ambiental, compreende-se que a existência da espécie humana depende da preservação e cuidado com o meio ambiente, a fim de que sejam garantidas condições mínimas de sobrevivência e bemestar tanto para a presente geração, quanto para as futuras. (BOFF, 2012, p. 47).

\section{b) Dimensão econômica}

A próxima dimensão da sustentabilidade a ser averiguada é a dimensão econômica, na qual, basicamente, busca-se um real equilíbrio entre a contínua produção de bens e serviços e a justa distribuição da riqueza. (PÓVOAS, 2015, p. 49).

FREITAS (2012, p. 65-67) sustenta que:

Dimensão econômica da sustentabilidade evoca, aqui a pertinente ponderação, o adequado "trade-off" entre eficiência e equidade, isto é, o sopesamento fundamentado, em todos os empreendimentos (públicos e privados), dos benefícios e dos custos diretos e indiretos (externalidades). A economicidade, assim, não pode ser separada da medição de con- 
sequências, de longo prazo. Nessa perspectiva, o consumo e a produção precisam ser reestruturados completamente, numa alteração inescapável do estilo de vida.

Assim, para o autor, a sustentabilidade tem o poder de criar uma nova economia, reestruturando as categorias e comportamentos, permitindo o surgimento de oportunidades com o planejamento de longo prazo e um sistema competente de incentivos e a eficiência norteada pela eficiência, não podendo, assim, ignorar-se a relação essencial entre a economia e sustentabilidade, pois, caso contrário, significaria deixar de ver o princípio numa de suas dimensões vitais. (FREITAS, 2012, p. 65-67).

No mesmo sentido, Sachs (1993, p. 25) reitera que a sustentabilidade econômica é possibilitada por uma alocação e gestão mais eficientes dos recursos e por um fluxo regular do investimento público e privado.

A dimensão estudada neste tópico também tem o condão de asseverar a finitude dos recursos naturais e, por conseguinte, buscar a sua preservação para que seja possível permitir para as gerações presentes e futuras as condições ideais para sua sobrevivência. (ANJOS; UBALDO, 2015, p. 287).

Logo, constata-se que:

[...] a sustentabilidade econômica extrapola o acúmulo de riquezas, bem como o crescimento econômico e engloba a geração de trabalho de forma digna, possibilitando uma distribuição de renda, promovendo o desenvolvimento das potencialidades locais e da diversificação de setores. Ela é possibilitada por alocação e gestão mais efetivas dos recursos e por um fluxo regular do investimento público e privado nos quais a eficiência econômica deve ser avaliada com o objetivo de diminuir a dicotomia entre os critérios microeconômicos e macroeconômicos. (MENDES, 2009, p. 53).

Nesta perspectiva, Boff (2012, p. 46) aponta que a causa da pobreza e da degradação da natureza se dá, principalmen- 
te, pelo tipo de desenvolvimento capitalista praticado, motivo pelo qual existe a necessidade de rever o ideal de economia utilizado, o qual tem sido o motivo da semeação de grandes problemas sociais e ambientais.

À vista disso, a dimensão econômica da sustentabilidade sustenta a ideia de que miséria e a pobreza extrema não são sustentáveis e se tornam problemas ambientais complicadíssimos (FERRER; CRUZ, 2017, p. 25), por isso, a necessidade de redistribuição das riquezas de cada local do mundo e de cada setor da economia.

\section{c) Dimensão social}

Passa-se a tratar a respeito da dimensão social da sustentabilidade, a qual, em suma, atua na proteção da diversidade cultural, garantia do exercício pleno dos direitos humanos e combate à exclusão social. (PÓVOAS, 2015, p. 49).

Nesta dimensão da sustentabilidade:

O objetivo é construir uma civilização do "ser", em que exista maior equidade na distribuição do "ter" e da renda, de modo a melhorar substancialmente os direitos e as condições de amplas massas de população e a reduzir a distância entre padrões de vida de abastados e não-abastados. (SACHS, 1993, p. 25).

Nesta perspectiva, objetiva-se maior equidade na distribuição da renda, de tal forma que possam ocorrer melhoras nos direitos e nas condições da população e, consequentemente, haja a ampliação da homogeneidade social, bem como a criação de oportunidades de empregos que garantam qualidade de vida e igualdade no acesso aos recursos e serviços sociais. (MENDES, 2009, p. 54).

Pondera-se, entretanto, que, para Boff (2012, p. 46), é extremamente complicado haver a construção de uma dimensão socialmente justa dentro do atual cenário de produção e consumo 
capitalista, o qual não propicia uma justiça social, tendo em vista a deficiência dos programas que os governos criam com repasses insuficientes de dinheiro para as grandes maiorias pobres.

Dessa forma, o grande destaque nesta dimensão é que as políticas públicas devem estar voltadas para a execução dos direitos sociais, porquanto o ser humano só irá respeitar a natureza e os seus recursos naturais se ele também for respeitado, for tratado com dignidade. (ANJOS; UBALDO, 2015, p. 287).

Acerca da abordagem da dimensão social da sustentabilidade, colaciona-se o seguinte conceito:

Dimensão social, no sentido de que não se admite o modelo do desenvolvimento excludente e iníquo. De nada serve cogitar da sobrevivência enfastiada de poucos, encarcerados no estilo oligárquico, relapso e indiferente, que nega a conexão de todos os seres vivos, a ligação de tudo e, desse modo, a natureza imaterial do desenvolvimento. [...] Válidas são apenas as distinções voltadas a auxiliar os desfavorecidos, mediante ações positivas e compensações que permitam fazer frente à pobreza medida por padrões confiáveis, que levem em conta necessariamente a gravidade das questões ambientais. Nesse ponto, na dimensão social da sustentabilidade, abrigam-se os direitos fundamentais sociais, que requerem os correspondentes programas relacionados à universalização, com eficiência e eficácia, sob pena de o modelo de governança (pública e privada) ser autofágico e, numa palavra, insustentável. (FREITAS, 2012, p. 58-59).

Para finalizar, verifica-se que por meio da dimensão social da sustentabilidade, é necessário criar novas regras que regulem os processos sociais, com o objetivo de se ter uma sociedade mais justa, mais inclusiva e mais humana. (FERRER; CRUZ, 2017, p. 25).

\section{d) Dimensão espacial ou territorial}

A dimensão espacial da sustentabilidade, norteia-se em uma configuração rural-urbana mais equilibrada com uma me- 
lhor distribuição territorial de assentamentos humanos e também das atividades econômicas. (SACHS, 1993, p. 26).

Desta maneira, nesta dimensão ocorre a:

[...] busca de equilíbrio na configuração rural-urbana e melhor distribuição territorial dos assentamentos humanos e atividades econômicas; melhorias no ambiente urbano; superação das disparidades inter-regionais e elaboração de estratégias ambientalmente seguras para áreas ecologicamente frágeis a fim de garantir a conservação da biodiversidade e do ecodesenvolvimento. (MENDES, 2009, p. 52).

Sendo assim, nota-se que a sustentabilidade além de estar presente no setor econômico, onde se busca a distribuição justa de riquezas, conforme visto no tópico 1.2.2, manifesta-se, igualmente, na distribuição de áreas ocupadas pelos seres humanos, assim como a organização desses espaços, com o escopo de criar regras para melhor conservação e recuperação do meio ambiente em cada espaço, principalmente, nos mais degradados.

\section{e) Dimensão cultural}

Quanto ao aspecto da dimensão cultural, segundo entendimento do autor Sachs (1993, p. 27), essa se caracteriza como uma evolução do processo de desenvolvimento cultural, próprio de cada região, contemplando, assim:

[...] a busca das raízes endógenas dos modelos de modernização e dos sistemas rurais integrados de produção, privilegiando processos de mudança no seio da continuidade cultural e traduzindo o conceito normativo de eco desenvolvimento em uma pluralidade de soluções particulares, que respeitem as especificidades de cada ecossistema, de cada cultura e de cada local.

Nesta conjuntura, a dimensão cultural deve promover, preservar e divulgar a história, tradições e valores regionais, acompanhando sempre suas transformações e, claro, garantindo a toda a população o acesso à informação e ao conhecimen- 
to para que possam investir na construção, reforma ou restauração de equipamentos culturais. (MENDES, 2009, p. 55).

Segundo Boff (2012, p. 50):

Aqui se deixa para trás a obsessão pelo lucro e pelo crescimento material, abrindo espaço para uma forma de habitar a Terra que condiz melhor com a natureza humana que sempre produz cultura, também na área da produção e do consumo. Esta dimensão da cultura, entretanto, não pode ser tomada em separado das outras dimensões, mas será seguramente uma das fontes a partir das quais beberá um novo paradigma de convivência. Então, sim, o desenvolvimento poderá ser considerado sustentável.

Dessa forma, pode-se dizer que a dimensão cultural da sustentabilidade contribui para instruir a qualidade de vida pelo exercício da cidadania cultural, sendo que a oportunidade de exercer tal papel deve ser colocada à disposição de toda a sociedade de forma igualitária, a fim de que todos tenham acesso à essa garantia. (SILVA; SOUZA; LEAL, 2012, p. 36).

\section{f) Dimensão política (nacional e internacional)}

Neste tópico, tratar-se-á acerca da dimensão política nacional e internacional da sustentabilidade.

Sobre a dimensão política nacional da sustentabilidade, verifica-se que essa está baseada na democracia e na apropriação universal dos direitos humanos, bem como no progresso da capacidade de cada Estado em executar o seu projeto nacional em cooperação com os empreendedores e em coesão social. (MENDES, 2009, p. 52-56).

Ou seja, a dimensão supramencionada tem como objetivo fazer com que ocorra a efetiva atuação da população e também das empresas nas decisões políticas que envolvam os problemas ambientais de seus territórios, bem como na busca de meios para solucioná-los. 
Em outra vertente, tem-se a dimensão política internacional da sustentabilidade, cuja abrangência atende às necessidades ambientais em âmbito global, sendo imprescindível a cooperação mútua de todas as nações para com eficácia atuarem:

\begin{abstract}
[...] na prevenção de guerras, na garantia da paz e na promoção da cooperação internacional e na aplicação do princípio da precaução na gestão do meio ambiente e dos recursos naturais; prevenção da biodiversidade e da diversidade cultural; gestão do patrimônio global como herança da humanidade; cooperação científica e tecnológica internacional. (MENDES, 2009, p. 52).
\end{abstract}

Assim, verifica-se que tanto no âmbito nacional, quanto no âmbito internacional, a participação e cooperação de todas as pessoas é essencial para o desenvolvimento da sustentabilidade em todas as áreas, principalmente, através da política, porquanto ela exerce grande influência e poder sobre a sociedade.

\title{
g) Dimensão jurídico-política
}

No que concerne à dimensão jurídico-política da sustentabilidade, apura-se que essa se relaciona com a seara constitucional, no que tange ao direito ao meio ambiente, pois, como visto anteriormente, a proteção e preservação ambiental é um direito previsto na Carta Magna que deve ser garantido a todos os indivíduos.

Partindo dessa premissa, é imprescindível mencionar a conexão que a sustentabilidade possui com a tutela jurídico-política quanto ao aspecto ambiental. Nestes termos:

[...] ecoa no sentido de que a sustentabilidade determina, com eficácia direta e imediata, independentemente de regulamentação, a tutela jurídica do direito ao futuro e, assim, representa-se como dever constitucional de proteger a liberdade de cada cidadão (titular de cidadania ambiental ou ecológica), nesse status, no processo de estipulação intersubjetiva do conteúdo intertemporal dos direitos e deveres 
fundamentais das gerações presentes e futuras, sempre que viável diretamente. (FREITAS, 2012, p. 67).

Pode-se afirmar, então, que a sustentabilidade, como visto, é um princípio constitucional, pois está disposta no artigo 225, da Constituição da República Federativa do Brasil de 1988 e, sendo assim, tem o poder de determinar, sem prejuízo das disposições internacionais, a eficácia dos direitos fundamentais de todas as dimensões. (FREITAS, 2012, p. 71).

\section{h) Dimensão ética}

O conceito de ética é extremamente amplo e complexo de se categorizar, devido à abstração quanto à multiplicidade de significados criados de acordo com o entendimento de cada indivíduo.

Porém, no que tange à dimensão ética da sustentabilidade, verifica-se que ela é conceituada do seguinte modo:

Dimensão ética, no sentido de que todos os seres possuem uma ligação intersubjetiva e natural, donde segue a empática solidariedade como dever universalizável de deixar o legado positivo na face da terra, com base na correta compreensão darwiniana de seleção natural, acima das limitações dos formalismos kantianos e rawlsianos. (FREITAS, 2012, p. 67).

E mais:

A dimensão ética da sustentabilidade, desse modo, reclama, sem subterfúgios, uma ética universal concretizável, com o pleno reconhecimento da dignidade intrínseca dos seres vivos em geral, acima dos formalismos abstratos e dos famigerados transcendentalismos vazios. Ademais, uma concepção ética consistente da sustentabilidade é, por definição, a de longe espectro. Permite perceber o encadeamento de condutas, em lugar do mau hábito de se deixar confinar na teia do imediato, típico erro cognitivo dos que não entendem o impacto retroalimentador das ações e das omissões. [...] Em síntese, a ética da sustenta- 
bilidade reconhece (a) a ligação de todos os seres, acima do antropocentrismo estrito, (b) o impacto retroalimentador das ações e das omissões, (c) a exigência da universalização concreta, tópico-sistemática do bem-estar e (d) o engajamento numa causa que, sem negar a dignidade humana, proclama e admite a dignidade dos seres vivos em geral. (FREITAS, 2012, p. 68-71).

Assim, em síntese, "[...] a dimensão ética preocupa-se em preservar a ligação intersubjetiva e natural entre todos os seres, projetando-se aí os valores de solidariedade e cooperação, que afastam a 'coisificação' do ser humano." (SOUZA; GARCIA, 2016, p. 137).

Portanto, denota-se que a sustentabilidade não tem sua perspectiva limitada apenas ao meio ambiente, mas abrange também os indivíduos que interagem com esse complexo, analisando-os sob a ótica das características inerentes a cada pessoa. Diante disso, depreende-se que o ser humano só irá tratar o meio ambiente com a dignidade que lhe é devida quando esse for compreendido como parte de todo esse sistema.

\section{i) Dimensão psicológica}

O termo "psicologia" é usualmente compreendido como "[...] uma ciência que trata da mente e dos fenômenos, estados e processos mentais; e ciência do comportamento humano e animal em suas relações com o meio social e físico." (MICHAELIS, 2017).

No âmbito da sustentabilidade, o referido termo é usado para designar o estudo do ser humano nas suas relações com as demais dimensões, como a cultural, a social, a política e a econômica. À vista disso, a dimensão psicológica é indispensável para o entendimento e compreensão da sustentabilidade, pois, por meio da psicologia, pode-se constatar e averiguar a relação do ser humano com o meio ambiente. (MENDES, 2009, p.52). 


\section{j) Dimensão tecnológica}

A última dimensão a ser abordada é a dimensão tecnológica da sustentabilidade. Como dito anteriormente, a preocupação com o meio ambiente tem sido cada vez maior, frente aos inúmeros problemas ambientas que o planeta Terra tem enfrentado e, por isso, várias soluções têm sido encontradas para alcançar uma sociedade mais sustentável por meio das tecnologias.

Isso porque, "[...] efetivamente, não se pode descrever a sociedade atual sem levar em conta a influência que a tecnologia exerce sobre a sua estrutura e sobre as relações que nela se estabelecem." (FERRER; CRUZ, 2017, p. 39).

Logo, considerando que a tecnologia está extremamente presente nos dias atuais, na vida de todas as pessoas, em todas as classes sociais, bem como em todos os setores da economia, verifica-se que:

Se a Sustentabilidade pretende a construção de um modelo social viável, já foi visto que, sem atender ao fator tecnológico, não se pode sequer imaginar como será essa sociedade. As clássicas dimensões da Sustentabilidade estão indefectivelmente determinadas por esse fator. (FERRER; CRUZ, 2017, p. 40).

A exemplo de como a tecnologia ajudará na propagação da sustentabilidade, tem-se que "[...] as soluções deverão chegar por caminhos que unicamente a ciência poderá oferecer, adotando um novo modelo energético baseado em tecnologias limpas, produzindo sem resíduos e revertendo alguns dos efeitos nocivos já causados [...]". (FERRER; CRUZ, 2017, p. 41).

Outrossim, a dimensão tecnológica da sustentabilidade pode também ser definida da seguinte forma:

Os processos de eficiência que podem economizar energia e recursos, diminuir poluição, aumentar produtividade com distribuição equitativa de renda e evitar desperdício 
de capital, passam pela Educação e Inovação Tecnológica norteadas pela conservação ambiental. Mudanças em design de produto, a aplicação da tecnologia da informação em controle e medição, a utilização de novos materiais de baixo impacto ambiental, o aproveitamento de materiais reciclados, a agregação de valor a resíduos (emissão zero), o uso de substâncias de base natural e capacitação de trabalhadores conscientes do processo em que estão inseridos, são a plataforma de um desenvolvimento tecnológico ambientalmente saudável que podem diminuir nossa "pegada ecológica”. (CASAGRANDE, p. 03).

Finalmente, não se pode deixar de asseverar que todas as dimensões da sustentabilidade são incindíveis entre si e, deste modo, considerando o fato de que, atualmente, vive-se uma "tecno sociedade", o fator tecnológico permeia todas as dimensões apresentadas e estudadas. (FERRER; CRUZ, 2017, p. 45).

\section{CONCLUSÃO}

Na pesquisa em apreço, foi abordado o tema da sustentabilidade, tendo essa sido conceituada, em síntese, como a solução para a preservação do meio ambiente, a fim de que seja possível a manutenção da existência dos seres vivos no planeta Terra, isso, por meio de novas atitudes a serem implementadas no cotidiano de todos os indivíduos.

Neste sentido, analisou-se a presença de dimensões da sustentabilidade em várias áreas das relações humanas, sendo constatado a existência de dez dimensões, quais sejam: dimensão ecológica ou ambiental, dimensão econômica, dimensão social, dimensão espacial ou territorial, dimensão cultural, dimensão política (nacional e internacional), dimensão jurídico-política, dimensão ética, dimensão psicológica e dimensão tecnológica.

A dimensão ecológica ou ambiental está diretamente ligada com a preservação e cuidado com o meio ambiente. A dimen- 
são econômica traz a ideia de que é necessário a redistribuição das riquezas de cada local do mundo e de cada setor da economia, a fim de que sejam criadas condições para a existência da sustentabilidade. Já a dimensão social, está voltada para a execução de direitos sociais, pois, para esta, o ser humano só irá respeitar o meio ambiente se também for respeitado. Enquanto a dimensão espacial ou territorial está relacionada com a distribuição de áreas ocupadas pelos seres humanos, a fim de que o meio ambiente seja preservado.

Por sua vez, a dimensão cultural está ligada a garantia de acesso à cultura por todos, tendo em vista que a sustentabilidade está presente nesse meio também. A dimensão política nacional e internacional prevê a participação dos indivíduos na política, devido a influência desta na sociedade, a fim de que seja alcançada a sustentabilidade. A dimensão jurídico-política prega que a proteção ao meio ambiente é uma garantia constitucional. A dimensão ética trata a sustentabilidade sob a óptica do ser humano. A dimensão psicológica estuda a relação do ser humano com as demais dimensões. E, por fim, a dimensão tecnológica trata da ajuda da tecnologia na disseminação da sustentabilidade.

Assim, diante do presente estudo, foi possível observar que a sustentabilidade está presente em áreas de nossas vidas que não imaginamos e se pudermos parar e analisá-la com mais atenção, veremos que com a realização de pequenas práticas em cada relação que possuímos no dia a dia, é viável sim a preservação e recuperação do meio ambiente.

\section{REFERÊNCIAS}

ANJOS, Rafael Maas dos; UBALDO, Antonio Augusto Baggio e. O desporto como elemento indutor da sustentabilidade na sociedade de risco. In: SOUZA, Maria Cláudia da Silva Antunes de; ARMADA, Charles Alexandre. Sustentabilidade, meio ambiente e sociedade: reflexões e perspectivas [e-book]. Umuarama: Universidade Paranaense - UNIPAR, 2015. 
BOFF, Leonardo. Sustentabilidade: o que é - o que não é. Petrópolis, RJ: Vozes, 2012. BRASIL. Constituição (1988). Constituição da República Federativa do Brasil. Disponível em: <http://www.planalto.gov.br/ccivil_03/constituicao/constituicao.htm>. Acesso em: 20 abr. 2017.

BRAUN, Diogo Marcel Reuter; ROBL, Ronan Saulo. O ICMS ecológico como instrumento auxiliar para o alcance da sustentabilidade. In: SOUZA, Maria Cláudia da Silva Antunes de; ARMADA, Charles Alexandre. Sustentabilidade, meio ambiente e sociedade: reflexões e perspectivas [e-book]. Umuarama: Universidade Paranaense UNIPAR, 2015.

CASAGRANDE JUNIOR, Eloy Fassi. Inovação tecnológica e sustentabilidade: integrando as partes para proteger o todo. Disponível em: $<$ http://aplicweb.feevale.br/site/ files/documentos/pdf/23231.pdf $>$. Acesso em: 6 jun. 2017.

ELKINGTON, John. Sustentabilidade, canibais com garfo e faca. São Paulo: M. Books do Brasil Editora Ltda, 2012.

FERRER, Gabriel Real; CRUZ, Paulo Márcio. Direito, sustentabilidade e a premissa tecnológica como ampliação de seus fundamentos. In: SOUZA, Maria Cláudia da Silva Antunes de; REZENDE, Elcio Nacur. Sustentabilidade e meio ambiente: efetividades e desafios. Belo Horizonte: Editora D’Plácido, 2017.

FIORILLO, Celso Antonio Pacheco. Curso de direito ambiental brasileiro. 14. ed. São Paulo: Saraiva, 2013.

FREITAS, Juarez. Sustentabilidade: direito ao futuro. 2. ed. Belo Horizonte, MG: Fórum, 2012.

JACOBI, Pedro. Educação ambiental, cidadania e sustentabilidade. Cadernos de Pesquisa: revista de estudos e pesquisa em educação (Fundação Carlos Chagas), n. 118, mar. 2003.

MACHADO, Paulo Affonso Leme. Direito ambiental brasileiro. 23. ed. São Paulo: Malheiros, 2015.

MENDES, Jefferson Marcel Gross. Dimensões da Sustentabilidade. Revista das Faculdades Integradas Santa Cruz de Curitiba - Inove. Curitiba, v. 7, n. 2, p. 49-59, 2009. Disponível em: <http://www.santacruz.br/v4/download/revista-academica/13/cap5. pdf>. Acesso em: 18 mar. 2017.

MICHAELIS. Dicionário brasileiro da língua portuguesa. Editora Melhoramentos, 2017. Disponível em: $<\mathrm{http}: / /$ michaelis.uol.com.br/busca? $\mathrm{r}=0 \& \mathrm{f}=0 \& \mathrm{t}=0 \&$ palavra=psicologia $>$. Acesso em: 5 jun. 2017.

OLIVEIRA, Lucas Rebello de et al. Sustentabilidade: da evolução dos conceitos à implementação como estratégia nas organizações. Produção. São Paulo, v. 22, n. 1, p.70-82, jan./fev. 2012. Disponível em: <http://www.scielo.br/pdf/prod/v22n1/ aop_0007_0245.pdf $>$. Acesso em: 21 abr. 2017.

PÓVOAS, Monike Silva. O amor na sociedade de risco: a sustentabilidade e as relações de afeto. In: SOUZA, Maria Cláudia da Silva Antunes de; ARMADA, Charles Alexandre. Sustentabilidade, meio ambiente e sociedade: reflexões e perspectivas [e-book]. Umuarama: Universidade Paranaense - UNIPAR, 2015. 
SACHS, Ignacy. Estratégias de transição para o Século XXI: desenvolvimento e meio ambiente. São Paulo, SP: Studio Nobel: Fundação do desenvolvimento administrativo, 1993.

SARTORI, Simone; LATRÔNICO, Fernanda; CAMPOS, Lucila M. S. Sustentabilidade e desenvolvimento sustentável: uma taxonomia no campo da literatura. 2012. Disponível em: <http://www.scielo.br/pdf/asoc/v17n1/v17n1a02.pdf>. Acesso em: 20 abr. 2017.

SCHRAMM, Alexandre Murilo; CORBETTA, Janiara Maldaner. Desenvolvimento sustentável e sustentabilidade: conceitos antagônicos ou compatíveis? In: SOUZA, Maria Cláudia da Silva Antunes de; ARMADA, Charles Alexandre. Sustentabilidade, meio ambiente e sociedade: reflexões e perspectivas [e-book]. Umuarama: Universidade Paranaense - UNIPAR, 2015.

SILVA, Antonio Sergio da; SOUZA, José Gilberto de; LEAL, Antonio Cezar. A sustentabilidade e suas dimensões como fundamento da qualidade de vida. Geoatos: Revista Geografia em Atos, Presidente Prudente, v. 1, n. 12, p. 22-42, jun. 2012. Disponível em: <http://revista.fct.unesp.br/index.php/geografiaematos/article/view/1724/ sergiosilva>. Acesso em: 21 abr. 2017.

SOUZA, Maria Cláudia da Silva Antunes de; GARCIA, Rafaela Schmitt. Sustentabilidade e desenvolvimento sustentável: desdobramentos e desafios pós-relatório Brundtland. In: SOUZA, Maria Cláudia da Silva Antunes de; REZENDE, Elcio Nacur. Direito e sustentabilidade II [recurso eletrônico on-line]. Florianópolis: CONPEDI, 2016.

Recebido em: 09/05/2018

Aprovado em: 16/08/2018 